\title{
SOLOW DIFFERENTIAL EQUATIONS ON TIME SCALES - A UNIFIED APPROACH TO CONTINUOUS AND DISCRETE SOLOW GROWTH MODEL
}

\author{
Eva BRestovanská And Milan MedveĎ
}

\begin{abstract}
In this paper we reformulate the axioms of the well-known Solow macroeconomic growth model by means of the mathematical calculus on time scales. We derive a system of differential equations on a time scale $\mathbb{T}$ which is a generalization of the classical Solow fundamental differential equation for the continuous case as well as its discrete version. We also prove sufficient conditions for the exponential stability of equilibrium points of this system having positive coordinates. Applications of these results to the case of the Cobb-Douglas production function are given.
\end{abstract}

Mathematics subject classification (2010): 34N05, 26E70, 97E40, 97M10.

Keywords and phrases: $\Delta$-derivative, time scale, calculus on time scales, differential equations on time scales, production function, labor, capital, Solow model, exponential stability.

\section{REFERENCES}

[1] R. Agarwal, M. Bohner, D. O'Regan, Dynamic Equations on time scales: a survey, J. Math. Comp. and Appl. Math., 141, (2002), 1-26.

[2] E. Accinelly, J. G. BRIDA, Population growth and the Solow-Swan model, International journal of Ecological Economca and Statistic, 87 (2007), 54-63.

[3] M. Bohner, A. Peterson Advances in Dynamic Equations on Time Scales, Birkhaäuser, Boston, MA 2003.

[4] M. Bohner, A. Peterson, Dynamic Equations on Time Scales: An Introduction with Applications, Birkhaäuser, Boston, Basel, Berlin 2001.

[5] S. Brianzoni, C. Mammana, E. Mitcheti, Local and global dynamics in discrete time growt model with nonconcave production function, Discrete Dynamica in Nature and Society, Vol. 2012, Article ID 536570, 22 pages, doc:10.1155/2012/53657.

[6] S. Brianzoni, C. Mammana, E. Mitcheti, Complex dynamics in the neoclassical growth model with differential saving and non-constant labor force growth, Studies in Nonlinear Dynamics \& Econometrics, 11, 3 (2007).

[7] S. Brianzoni, C. Mammana, E. Mitcheti, Global attractor in Solow growth model with differential savings and endogenic labor force growth, AMS Periodicals, Modelling Measurement and Control D, 29, 2 (2008), 19-37.

[8] J. G. BRIDA, E.L. Maldonado, Closed form solutions to a generalization of the Solow growth model, Applied Mathematical Sciences, 1, 40 (2007), 1991-2000.

[9] J. G. BRIDA, J.S. PEREYRA, The Solow model in discrete time and decreasing population growth rate, Economic Bulletin, 3, 41 (2008), 1-14.

[10] D. Cheban, C. Mammana, E. Mitchetti, Global attractors of quasi-linear non-autonomous difference equations: A growth model with endogenous population growth, Nonlinear Analysis: Serie B, 14 (2013), 1716-1731.

[11] R. L. Devaney, An Introduction to Chaotic Dynamical Systems, Westview Press 2003.

[12] S. Hilger, Analysis on measure chains - A unified approach to continuous and discrete calculus, Results Math., 18, (1990), 18-56. 
[13] S. HiLger, Differential and difference calculus - unified!, Nonlinear Analysis, TMA, 30, 5 (1997), 2683-2694.

[14] M. Hirsch, S. Smale, R.L. Devaney, Differential Equations, Dynamical Systems, and An Introduction to Chaos, Elsevier, Amsterdam 2004.

[15] J. HOFFACKER, B. JACKSON, Stability results for higher dimensional equations on time scales, Int. J. Dynamical Systems and Differential Equations, 3, 1-2 (2011), 48-58.

[16] T. Kulik, C.C. Tisdell, Volterra integral equations on time scales, Basic qualitative and quantitative results with applications to initial value problems on unbounded domains, International Journal of Difference Equations (IJDE), 3, 1 (2008), 103-133.

[17] V. Lakshmikanhan, S. Sivarsundram, B. Kaymkcalan, Dynamic Systems on Measure Chains, Kluwer Academic Publishers, Netherlands 1996.

[18] M. Medvě̌, Fundamentals of Dynamical Systems and Bifurcation Theory, Adam Hilger, Bristol, Philadelphia and New York 1992.

[19] C. Potzsche, Chain rule and invariance principle on measure chain, J. Comput. Appl. Math., 141 (2002), 249-254.

[20] A.N. Sharkovs KiI, Coexistence of cycles of a continuous map of a line interval into itself, Ukrainskii Matematicheskii Zurnal, 16 (1964), 61-71.

[21] A.N. Sharkovskit, Yu. Maisterenko, E.Yu. Romanenko, Difference Equations and Their Applications, Kluwer Academic Publ. 1993.

[22] R.M. Solow, Contribution to the theory of economic growth, Quarterly Journal of Economics, 70, 1 (1956), 65-94.

[23] R.M. Solow, Technical change and the aggregate production function, Review of Economics and statistics, 39, 3 (1957), 312-320.

[24] C.C. Tisdell, A. ZAIDI, Basic qualitative and quantitative results for solutions to nonlinear, $d y$ namic equations on time scales, Nonlinear Anal., 68, 11 (2008), 3504-3524.

[25] C.C. TISDELL, A. ZAIDI, Successive approximations to solutions of dynamic dynamic equations on time scales, Comm. Appl. Nonlinear Anal., 16, 1 (2009), 61-87.

[26] H. WIESE, Intermediate Growth Theory, Springer-Verlag, Berlin, Heidelberg, New York 2006. 